\title{
CT study of the performance of reciprocating and oscillatory motions in flattened root canal areas
}

\section{Cacio MOURA-NETTO(a) \\ Renato Miotto PALO(b) \\ Larissa Fernanda PINTO(c) \\ Anna Carolina Volpi \\ MELLO-MOURA(d) \\ Gisele DALTOÉ(e) \\ Niels Salles Willo WILHELMSEN ${ }^{(f)}$}

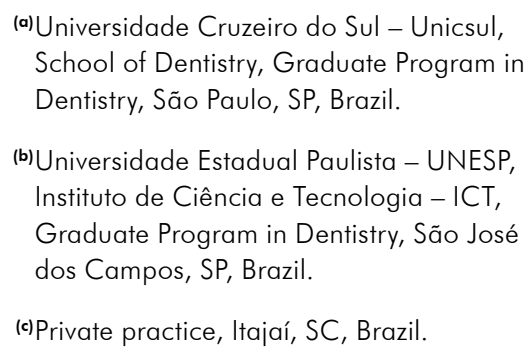

Declaration of Interests: The authors certify that they have no commercial or associative interest that represents a conflict of interest in connection with the manuscript.

Corresponding Author:

Cacio Moura-Netto

E-mail: caciomn@usp.br

DOI: 10.1590/1807-3107BOR-2015.vol29.0006

Submitted: May 08, 2014

Accepted for publication: Aug 13, 2014

Last revision: Oct 03, 2014

\begin{abstract}
Root canal preparation is an important step in endodontic treatment. The anatomical complexity of the middle third of the root compromises the effective cleaning of this area. Thus, advances have been made in instrumentation techniques and instruments for this purpose. The aim of this study was to evaluate the effects of three different instrumentation systems on the enlargement of the middle thirds of root canals in mandibular incisors. The preparation methods used were the reciprocating systems Reciproc (Group I) and WaveOne (Group II) and the oscillatory system Tilos (Group III). Comparisons were made by three-dimensional image reconstruction with cone-beam computed tomography before and after instrumentation. Changes in area, perimeter, centering ability, and pattern of preparation were analyzed. The results were subjected to ANOVA complemented by the Tukey's test. Changes in area, perimeter, and tendency of transportation showed similar results among groups. The transportation index of the Tilos system was significantly lower than that of the other groups. Qualitative analysis of the preparation pattern showed that the Tilos system had a more uniform preparation, although Reciproc and WaveOne preparations appeared more rounded, incompatible with the original canal anatomy. There was similarity in the systems' performance on flattened areas, although the Tilos system presented a better pattern of root canal preparation and a lower index of transportation.
\end{abstract}

Keywords: Root Canal Preparation; Dental Instruments; Endodontics.

\section{Introduction}

Microorganisms are considered to be etiological factor in the development of periodontitis. ${ }^{1}$ Thus, the greatest challenge in endodontics is the effective cleaning of root canals, removing bacteria and their byproducts, necrotic pulp debris, and/or contaminated dentin., ${ }^{2,3}$ However, the complex internal anatomy of root canals compromises their proper cleaning. ${ }^{3,4,5}$

Isthmuses and irregularities are most prevalent in the middle thirds of flattened roots, because of straightening in the mesiodistal direction, such as in mandibular incisors, mandibular premolars, and the mesial roots of mandibular molars. Usually, instruments do not touch these areas, leaving microorganisms and debris, contributing to the failure of endodontic treatment. 6,7 
Nickel-titanium (NiTi) rotary instruments are commonly used in endodontic practice in an attempt to overcome anatomical complexities. ${ }^{8,9}$ In spite of offering many advantages, these instruments have limitations owing to their rotation kinematics, causing excessive preparation in some areas and leaving others untouched. ${ }^{7,10}$

Thus, stainless steel systems have been developed, such as the Tilos system, which comprises six instruments that perform symmetric oscillatory movements with 30 degrees of amplitude. ${ }^{11}$ Three stainless steel shaping files were designed for the preparation of the cervical and middle portions of the root canal, mostly in flattened and V-zone areas. ${ }^{7}$ The remaining instruments are the so-called transitional files and are comprised of three NiTi instruments to create a tapered shape to up to prepare the apical third. The system is complemented with five manual K-type Apical Finishing NiTi files designed for the final enlargement of the apical portion of the root. ${ }^{11,12}$

Recently, two new systems were developed for use in reciprocating motion designed for single-file root canal preparation: Reciproc (VDW, Munich, Germany) and WaveOne (Dentsply Maillefer, Ballaigues, Switzerland). ${ }^{9,13,14}$ These instruments are made of a new NiTi alloy called M-Wire, which gives more resistance to the file. Such reciprocating motion consists of a non-continuous rotary movement in a counterclockwise direction. . $^{3,14,15}$

On considering the variety of systems and kinematics available for root canal preparation, the aim of this study was to evaluate, through cone-beam volumetric tomography, anatomical changes in the middle thirds of the root canals of mandibular incisors after being shaped with the Reciproc, WaveOne, and Tilos systems.

\section{Methodology}

\section{Tooth selection and preparation}

This study was approved by the Ethics Committee of the Universidade Cruzeiro do Sul - Unicsul, São Paulo, Brazil (Protocol \#556.549).

Fifty-four human mandibular incisors extracted for periodontal reasons were used in this study. Before the experiment, the remaining soft tissue covering the root surface was removed with curettes, and the teeth were washed in tap water and subsequently radiographed in the mesiodistal direction to verify the presence of single canals, the absence of prior endodontic manipulation, resorption, and calcification within the canal.

After the coronal opening, a \#10 K file (Dentsply Maillefer, Ballaigues, Switzerland) was introduced into the full length of the tooth until visible at the apex. From this measurement, $1 \mathrm{~mm}$ was subtracted, and the working length was established. The samples were randomly divided into three groups ( $\mathrm{n}=18$ per group) according to the instrumentation system:

1. Group I: Reciproc R25 file (VDW, Munich, Germany);

2. Group II: WaveOne primary file size \#25 (Dentsply Maillefer, Ballaigues, Switzerland);

3. Group III: Tilos system (Ultradent Products, South Jordan, USA).

The specimens were fixed individually in acrylic plates for cell culture in 24 wells with dense condensation silicone (Zetaplus, Labordental, São Paulo, Brazil).

\section{Preoperative scanning}

An i-CAT cone-beam computed tomographic (CBCT) device (iCAT, Imaging Sciences International, Hatfield, PA, USA) was used in this study. Each plate was fixed on a CBCT platform, so that the laser beam of the apparatus was aimed at the central region. The protocol used to reconstruct each tooth involved volume size (field of view, FOV) of $16 \mathrm{~cm} \times 4 \mathrm{~cm}$, $0.125 \mathrm{~mm}$ isometric voxel, tube voltage of $120 \mathrm{kVp}$, tube current of $38.0 \mathrm{~mA}$, and slice thickness of 0.13 $\mathrm{mm}$. The exposure time was 26.9 seconds, and the filter used was the Sharpen $3 \times 3$. The scanning software was iCAT Vision $Q$ (Imaging Sciences International). After scanning, the images were checked for quality and subsequently identified and exported for analysis through iCAT Xoran software (Xoran version 3.1.62; Xoran Technologies, Ann Arbor, USA).

\section{Root canal instrumentation}

The kinematics used for WaveOne and Reciproc files involved the pecking motion without pressure. At each three pecks, the instrument was removed by brushing the canal walls. The movement was repeated until the working length was reached. 
The Tilos system was used in a $30^{\circ}$ oscillatory $4: 1$ low-speed handpiece (Ultradent Products) connected to an air micromotor, through brushing and filing kinematics, pushing the instrument against the root canal walls with no apical pressure. The canal was explored with a \#15 K file, and the other stainless steel shaping files were used $3 \mathrm{~mm}$ shorter than the working length. With the \#20 hand file, the working length was recapitulated. The apical preparation was completed with a NiTi \#25 0.08 at the working length.

After the use of each instrument, the canals were irrigated with $1 \mathrm{ml}$ of $2.5 \%$ sodium hypochlorite (Fórmula e Ação, São Paulo, Brazil). At the end of the preparation, a final irrigation was performed with $5 \mathrm{ml}$ of $2.5 \%$ sodium hypochlorite followed by $5 \mathrm{ml}$ of EDTA at $17 \%$ (Fórmula e Ação) for 3 minutes.

\section{Postoperative Scanning}

Postoperative scanning was performed according to the same protocol as that for preoperative scanning.

For evaluation of the preparation systems, the roots were measured, and an axial slice from the same middle point of the root was selected and analyzed according to the following requirements:

\section{Change in area}

The change in area was calculated by subtracting the initial area in $\mathrm{mm}^{2}$ (prior to preparation) from the final area (after preparation) in the same axial crosssections of each canal in the middle third region.

\section{Perimeter changes}

As with area change, the initial perimeter of the same axial cross-section was subtracted from the final perimeter, for evaluation of the extent of root canal wall preparation.

\section{Tendency to transportation}

The thickness of the mesial and distal root canal walls of the same cross-section of the middle third was measured before and after preparation. The following formula was used to calculate the tendency to transportation:

$(\mathrm{m} 1$ - $\mathrm{m} 2)-(\mathrm{d} 1$ - d2)

Where $\mathrm{m} 1$ is the thickness of the mesial root canal wall before instrumentation and $\mathrm{m} 2$ is the thickness after endodontic preparation; $\mathrm{d} 1$ and $\mathrm{d} 2$ are the same for the distal root canal wall.

In this analysis, results equal to zero indicate the absence of canal transportation. Positive results indicate transportation to the mesial root canal wall, and negative results indicate transportation to the distal root canal wall.

\section{Transportation index}

Theamount of rootcanal transportation wascalculated according to a formula proposed by Gambill et al.:16

$|(\mathrm{m} 1-\mathrm{m} 2)-(\mathrm{d} 1-\mathrm{d} 2)|$

A result equal to zero indicates perfect centralization in the mesio-distal direction. The farther from zero, the greater the transportation index, whether for the mesial or distal root canal wall.

\section{Statistical analysis}

Data were statistically analyzed with BioEstat 5.0 software (Manuel Ayres, Belém, Brazil). Normality of distribution was checked by the Kolmogorov-Smirnov test. The values were subjected to analysis of variance (ANOVA) and Tukey's test, with a significance level of $95 \%(a=0.05)$.

\section{Qualitative analysis of the pattern of root canal preparation}

The selected CBCT axial slice images were opened in Adobe Photoshop CS6 (Adobe Systems Inc., San Jose, USA), and the root canal areas before and after preparation were outlined. The preoperative areas were then filled in blue, with the postoperative area in red. After that, pre- and postoperative images were superimposed for analysis of the pattern of root canal preparation of each system.

\section{Results}

\section{Area and perimeter changes}

The mean values and standard deviations of the differences between the final and initial areas and final and initial perimeters are shown in Table 1.

The mean difference between the initial and final areas was not statistically significant among groups. There was no statistically significant difference among groups in mean difference of perimeter. 


\section{Root canal transportation}

Themean values of the tendency to transportation and transportation index are shown in Table 2. The systems showed low values for tendency to transportation. Tilos showed the lowest values, followed by Reciproc and WaveOne, but there was no statistically significant differenceamong groups. The lowest mean transportation index was found in the Tilos group, assuming that this system produced less transportation of the root canal when compared with other systems $(p<0.01)$, followed by Reciproc and WaveOne, which showed no statistically significant difference between them.

\section{Qualitative analysis of the pattern of root canal preparation}

Figure 1 shows preoperative and postoperative images and the superposition of both images for each group, to illustrate the root canal preparation pattern of each system. It can be noted that both reciprocating systems provided a more circular pattern of preparation. Otherwise, the Tilos system promoted a more uniform preparation, with more consideration for the initial root canal anatomy.

\section{Discussion}

Anatomical variations of the root canal play an important role in the success of endodontic therapy because, in flattened canals, necrotic tissue or portions of the smear layer may remain in the projections and

Table 1. Mean differences between the initial and final area and perimeter.

\begin{tabular}{lcc}
\hline System & $\Delta$ Area $\left(\mathrm{mm}^{2}\right)$ & $\Delta$ Perimeter $(\mathrm{mm})$ \\
\hline Reciproc & $0.461 \pm 0.297$ & $0.753 \pm 0.347$ \\
WaveOne & $0.607 \pm 0.319$ & $0.688 \pm 0.276$ \\
Tilos & $0.475 \pm 0.250$ & $0.723 \pm 0.323$ \\
ANOVA & n.s. & n.s. \\
\hline
\end{tabular}

n.s.: not significant

Table 2. mean values of the tendency of transportation and transportation index.

\begin{tabular}{lcc}
\hline System & Tendency $(\mathrm{mm})$ & Index $(\mathrm{mm})$ \\
\hline Reciproc & $0.014^{\mathrm{a}}$ & $0.086^{\Uparrow}$ \\
WaveOne & $0.065^{\circ}$ & $0.116^{\AA}$ \\
Tilos & $-0.004^{\circ}$ & $0.026^{\S}$
\end{tabular}

*Different letters or symbols denote significant statistical difference. branches, preventing proper biological sealing. ${ }^{6,7,17,18,19}$ This is due to inappropriate endodontic preparation that does not reach such areas. For analysis of this issue, mandibular incisors were selected for this study.

Various methods have been used to compare root canal morphology before and after preparation. Conventional radiographs are limited to twodimensional analysis of a three-dimensional structure..$^{20}$ Thus, CBCT is an important tool in the study of root canal morphology. ${ }^{17,21,22}$ In the present study, computed tomography allowed the visualization of morphological characteristics in three dimensions, leading to an understanding of the action of the instruments in the root canal. The literature presents different analyses about instrumentation techniques; however, until the most recent search (March, 2014),

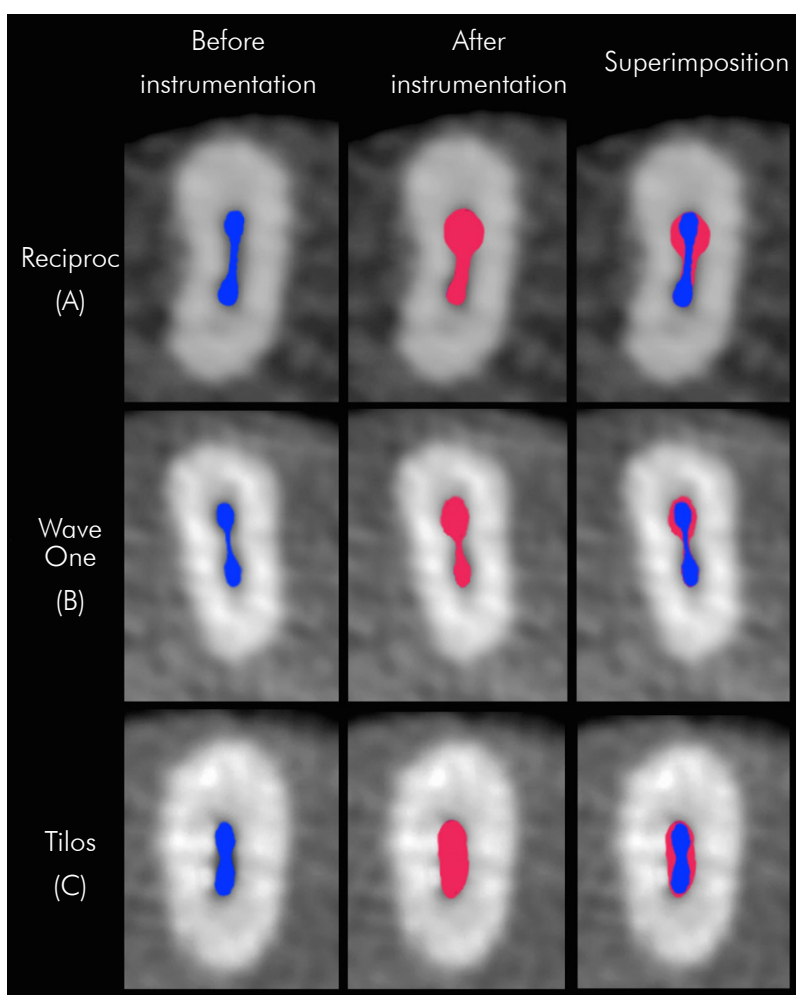

Figure 1. Comparative images of the middle thirds of the mandibular incisors before and after instrumentation and their superposition. The quality analysis of the preparation pattern in the middle thirds of the lower incisors showed that Reciproc and WaveOne systems (A and B, respectively) provided a more rounded preparation, incompatible with the original canals, whereas the Tilos (C) system resulted in a more uniform preparation around the perimeter of the root canal, in accordance with its anatomy. 
few studies have compared the instrumentation of at least two of the systems used in the present research. Thus, our study was limited in terms of comparison with existing literature.

To ensure comparability among the groups, canal preparation respected the apical diameter, according to the recommendations of the manufacturers of Reciproc, Waveone, and Tilos files. Thus, we selected: Reciproc R25 (0.25-mm diameter and 0.08 taper in the first $3 \mathrm{~mm}$ ), which is indicated for canals considered narrow and partially or completely invisible on the radiograph; Waveone primary file $(0.25-\mathrm{mm}$ diameter and 0.08 taper in the first $3 \mathrm{~mm}$ ); and Tilos (apical file, 0.25 -mm diameter and 0.08 taper), used in thin canals.

The results for changes in area and perimeter were similar among the groups, which showed no statistically significant differences among them. This fact could be explained by the influence of system kinematics, because with Reciproc and WaveOne, pecking movements were performed to reach the working length associated with brushing movements to remove the instrument from the canal. The Tilos system comprises six instruments, three of stainless steel (SS) and three made with NiTi alloy. The SS files work only in a brushing motion, pressing the instrument against the walls of the root canal. This kinematics using SS files, in theory, is able to touch more canal walls, based on the principles of conventional manual instrumentation. There was no difference among the mean perimeters of the studied groups. Similar results were found in previous studies testing Reciproc and WaveOne instruments. ${ }^{14,23,24}$ Perhaps this result would be different if Reciproc and WaveOne were used only in pecking movements.

Another factor assessed was the ability of the instrument to remain centered in the root canal

\section{References}

1. Schilder H. Cleaning and shaping the root canal. Dent Clin North Am. 1974 Apr;18(2):269-96.

2. Taşdemir T, Aydemir H, Inan U, Unal O. Canal preparation with Hero 642 rotary Ni-Ti instruments compared with stainless steel hand k-file assessed using computed tomography. Int Endod J. 2005 Jun;38(6):402-8.

3. Mauger MJ, Schindler WG, Walker WA. An evaluation of without causing transportation. The results showed that all systems had a minor tendency to deviate, but with low values, and with no statistically significant difference among groups. In relation to the transportation index, the Tilos system had the lowest rate of root canal decentralization.

When the shapes of the canal before and after instrumentation were compared, it was clearly seen that the preparation pattern with Reciproc and WaveOne was more rounded and limited than in the canals instrumented with the Tilos system, which showed a more homogeneous preparation in accordance with the original anatomy. Although the "reciprocating" movement was used in Reciproc and WaveOne, this motion actually promotes a rotation of the file within the canal, which contributes to a rounded conical shape in its final preparation, as previously described by other studies. ${ }^{14,23,24}$ This final configuration does not respect the common original root canal anatomy of mandibular incisors, mainly in the middle thirds, which is the area of greatest flattening.,10 This final shape could lead to untouched areas with remaining debris, smear layer, and bacteria. Clinically, this fact could decide the outcome of the endodontic treatment, decreasing the success rate. Therefore, these findings should be an alert in the practice of endodontics, because the easier and faster method of endodontic preparation claimed by reciprocating systems is not always the best choice for proper treatment.

\section{Conclusion}

Considering the limitations of the present study, it can be concluded that all tested systems performed similarly in terms of morphometric changes on flattened areas, although the Tilos system showed a more anatomic pattern of preparation and a significantly lower index of transportation.

canal morphology at different levels of root resection in mandibular incisor. J Endod. 1998 Sep;24(9):607-9.

4. Marchesan MA, Arruda MP, Silva-Sousa YT, Saquy PC, Pecora JD, Sousa-Neto MD. Morphometrical analysis of cleaning capacity using niquel-titanium rotary instrumentation associated with irrigating solutions in mesio-distal flattened root canals. J Appl Oral Sci. 2003 Mar;11(1):55-9. 
5. Loizides A, Eliopoulos D, Kontakiotis E. Root canal transportation with a Ni-Ti rotary file system and stainless steel hand files in simulated root canals. Quintessence Int. 2006 May;37(5):369-74.

6. Metzger Z, Zary R, Cohen R, Teperovich E, Paqué F. The quality of root canal preparation and root canal obturation in canals treated with rotary versus self-adjusting files: a threedimensional micro-computed tomographic study. J Endod. 2010 Sep;36(9):1569-73.

7. Moura-Netto C, Palo RM, Camargo CH, Pameijer CH, Bardauil MR. Micro-CT assessment of two different endodontic preparation systems. Braz Oral Res. 2013 Jan-Feb;27(1):26-30.

8. Rasquin LC, Carvalho FB, Lima RKP. In vitro evaluation of root canal preparation using oscillatory and rotary systems in flatteded root canals. J Appl Oral Sci 2007 Feb;15(1):65-9.

9. Kim HC, Kwak SW, Cheung GS, Ko DH, Chung SM, Lee W. Cyclic fatigue and torsional resistance of two new nickeltitanium instruments used in reciprocation motion: Reciproc versus WaveOne. J Endod 2012 Apr;38(4):541-4.

10. Gu L, Wei X, Ling J, Huang X. A microcomputed tomographic study of canal isthmuses in the mesial root of mandibular first molars in a Chinese population. J Endod 2009 Mar;35(3):353-6.

11. Nordmeyer S, Schnell V, Hülsmann M. Comparison of root canal preparation using Flex Master Ni-Ti and Endo-Eze AET stainless steel instruments. Oral Surg Oral Med Oral Pathol Oral Radiol Endod. 2011 Feb;111(2):251-9.

12. Zmener O, Pameijer $\mathrm{CH}$, Alvarez Serrano S, Hernandez SR. Cleaning efficacy using two engine-driven systems versus manual instrumentation in curved root canals: a scanning electron microscopic study. J Endod. 2011 Sep;37(9):1279-82.

13. De-Deus G, Arruda TE, Souza EM, Neves A, Magalhães K, Thuanne E, et al. The ability of the Reciproc R25 instrument to reach the full root canal working length without a glide path. Int Endod J. 2013 Oct;46(10):993-8.

14. Berutti E, Chiandussi G, Paolino DS, Scotti N, Cantatore G, Castellucci A, et al. Canal shaping with WaveOne Primary reciprocating files and ProTaper system: a comparative study. J Endod. 2012 Apr;38(4):505-9.
15. Plotino G, Grande NM, Porciani PF. Deformation and fracture incidence of Reciproc instruments: a clinical evaluation. Int Endod J. 2014 Apr 22. DOI: 10.1111/iej.12302. Epub ahead of print

16. Gambill JM, Alder M, del Rio CE. Comparison of nickeltitanium and stainless steel hand-file instrumentation using computed tomography. J Endod. 1996 Jul;22(7):369-75.

17. Neelakantan P, Subbarao C, Ahuja R, Subbarao CV, Gutmann JL. Cone-beam computed tomography study of root and canal morphology of maxillary first and second molars in an Indian population. J Endod. 2010 Oct;36(10):1622-7.

18. Endal U, Shen Y, Knut A, Gao Y, Haapasalo M. A high-resolution computed tomographic study of changes in root canal isthmus area by instrumentation and root filling. J Endod. 2011 Feb;37(2):223-7.

19. Berutti E, Paolino DS, Chiandussi G, Alovisi M, Cantatore G, Castellucci A, et al. Root canal anatomy preservation of WaveOne reciprocating files with or without glide path. J Endod. 2012 Jan;38(1):101-4.

20. Bürklein S, Hinschitza K, Dammaschke T, Schäfer E. Shaping ability and cleaning effectiveness of two single-file systems in severely curved root canals of extracted teeth: Reciproc and WaveOne versus Mtwo and ProTaper. Int Endod J. 2012 May;45(5):449-61.

21. Marzouk AM, Ghoneim AG. Computed tomographic evaluation of canal shape instrumented by different kinematics rotary nickel-titanium systems. J Endod. 2013 Jul;39(7):906-9.

22. Versiani MA, Pascon EA, Sousa CJ, Borges MA, Sousa-Neto MD. Influence of shaft design on the shaping ability of 3 nickel-titanium rotary systems by means of spiral computerized tomography. Oral Surg Oral Med Oral Pathol Oral Radiol Endod. 2008 Jun;105(6):807-13.

23. Versiani MA, Leoni GB, Steier L, De-Deus G, Tassani S, Pécora JD, et al. Micro-computed tomography study of oval-shaped canals prepared with the self-adjusting file, Reciproc, WaveOne, and ProTaper universal systems. J Endod. 2013 Aug;39(8):1060-6.

24. Dietrich MA, Kirkpatrick TC, Yaccino JM. In vitro canal and isthmus debris removal of the self-adjusting file, K3, and WaveOne files in the mesial root of human mandibular molars. J Endod. 2012 Aug;38(8):1140-4. 